\title{
Triceps Brachii Tendon Reconstruction with V-Y Plasty: Indication and Functional Results of a Case at Bouaké Teaching Hospital
}

\author{
Krah Koffi Léopold"1, Sery Bada Léopold1, Kone Samba², Digbeu Kévin'1, Assere Arnaud1, \\ Kouassi Aya Natacha1, Kouassi Eric ${ }^{1}$, M'Bra Innocent $^{1}$, Yao Loukou Blaise', Kodo Michel1 \\ ${ }^{1}$ Traumatology and Orthopedics Surgery of the University Hospital of Bouake, Bouaké, Côte d'Ivoire \\ ${ }^{2}$ Traumatology and Orthopedics Surgery of the University Hospital of Abidjan, Abidjan, Côte d'Ivoire \\ Email: kkoffileopold@gmail.com
}

How to cite this paper: Léopold, K.K., Léopold, S.B., Samba, K., Kévin, D., Arnaud, A., Natacha, K.A., Eric, K., Innocent, M'B., Blaise, Y.L. and Michel, K. (2017) Triceps Brachii Tendon Reconstruction with V-Y Plasty: Indication and Functional Results of a Case at Bouaké Teaching Hospital. Open Journal of Orthopedics, 7, 396-399.

https://doi.org/10.4236/ojo.2017.712041

Received: October 7, 2017

Accepted: November 27, 2017

Published: November 30, 2017

Copyright () 2017 by authors and Scientific Research Publishing Inc. This work is licensed under the Creative Commons Attribution International License (CC BY 4.0).

http://creativecommons.org/licenses/by/4.0/

\begin{abstract}
Repair of an old lesion of the triceps brachii tendon is infrequent. A V-Y plasty was performed 4 years after the injury in an adult. Post traumatic osteoarthritis limits functional outcomes. The patient is satisfied.
\end{abstract}

\section{Keywords}

Reconstruction, Tendon, Triceps Brachii

\section{Introduction}

Several techniques have been described for reconstruction of old lesions of the triceps brachii tendon [1] [2] [3]. The V-Y plasty gives good result [4]. We have experimented with a patient we report in order to contribute to the study of this technique and to highlight advantages and disadvantages.

\section{Case Report}

Miss A. B, 35 years old, was the victim of a road accident in 2008. She presented a dislocation-fracture of the right elbow that would have been treated by the traditional healer. Persistence of limited elbow movements required orthopedic consultation in 2012. Active flexion and extension were $110^{\circ}$ and $-45^{\circ}$. Arm abduction was limited at the shoulder. Prono-supination was normal. Standard radiography revealed triceps tendon avulsion and osteoarthritis of the elbow (Figure 1).

A V-Y plasty of the tendon was performed. A small pellet of avulsion bone 


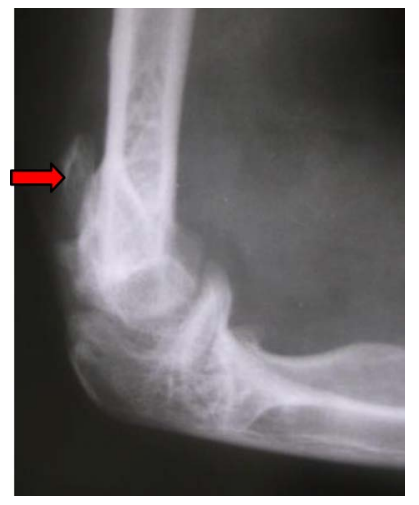

Figure 1. X-ray showing an ascending olecranon bone pellet and elbow osteoarthritis. The red arrow indicates bone pellet.

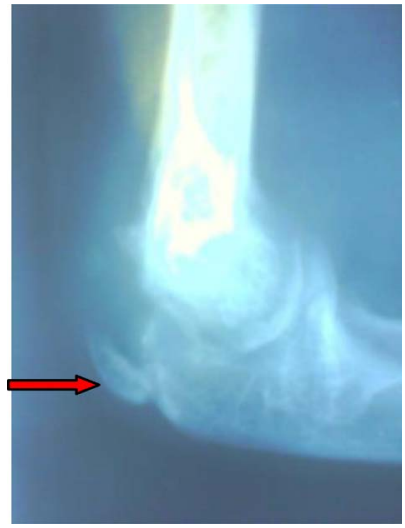

Figure 2. Radiograph control after surgery. Bone pellet (arrow in red) on the olecranon is not anatomical but there is a contact.

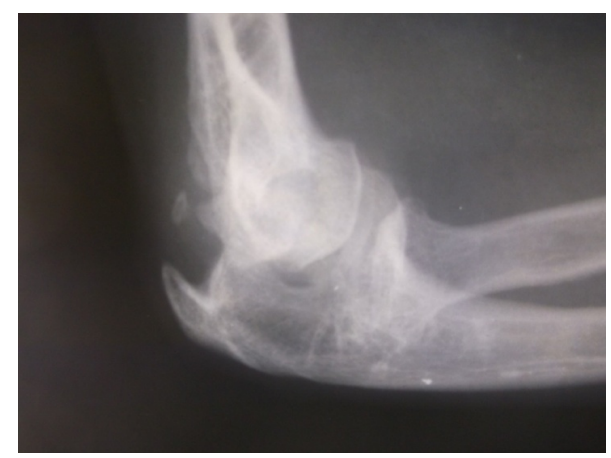

Figure 3. X-ray at 12 months showing a fusion with posterior olecranon outgrowth.

associated was fixed on the olecranon by bone stitches (Figure 2).

A brachio-palmar cast was made, elbow in incomplete extension. Iatrogenic ulnar neuropathy evolved favorably in 6 months. Fusion of the bone was made (Figure 3).

At 24 months' follow-up a $40^{\circ}$ elbow extension was obtained and limb abduction was possible beyond the shoulder.

Post-traumatic osteoarthritis limits movement. The patient is satisfied with the functional result. 


\section{Discussion}

Impossibility of writing on the board on a height beyond the head aroused interest of surgery of our patient looking for a job in education. Brachial triceps is an elevator muscle of the forearm on the arm. It is explored with arm in $90^{\circ}$ abduction, bending of elbow at $90^{\circ}$ and the forearm in prono-supination thumb turned towards patient. Elbow extension deficit from this position means triceps brachii tendon lesion [4]. Rupture can be done on muscle but tendinous lesion is common [4] [5] [6]. Radiograph elbow profile confirms the bone lesions and the ultrasound of the triceps diagnoses the muscular lesions. MRI is useful in old lesions [5]. Traumatic etiology is common but weakness of the tendon may be related to hyperthyroidism or cortisone infiltration [7] [8] [9] [10]. Late diagnosis is due to insufficient initial clinical and radiological investigation or a delay of consultation. Old lesions are difficult to treat because of tendon retraction associated with other lesions including elbow osteoarthritis [2] [3] [4]. Reconstructive techniques are performed by tendon graft or elongation [1] [2] [3] [4]. The $\mathrm{V}-\mathrm{Y}$ reconstruction of the triceps brachii tendon has been described by Yazdi [4]. It is a technique that allows an extension of the tendon. Patient is in lateral decubitus. A pneumatic tourniquet is useful. In our case we did not do for lack of material. This allowed us to have full access to the triceps muscle. Incision is posterior median. Tendon is highlighted until its muscular junction. Gap between the end of the tendon and its olecranon insertion zone is measured. The inverted $\mathrm{V}$ section of tendon is at the edge of its muscular junction retaining tendino-muscular fibers. Rehabilitation of tendon in case of avulsion may require bone stitches. In our case we made it with non-resorbable wire of $1 \mathrm{~mm}$ caliber. There is a risk of ulnar nerve injury observed in our case during bone stitched. Prior exposure of the nerve may be helpful. Tendon suture is made by an inverted Y suture. After closure incision, an immobilization of the elbow is not mandatory. It has been in our case to avoid mobilization without authorization. At the 2 years follow-up, we have no sign of rerupture. Supervising should be continued because in the triceps tendon repair, $6 \%$ of cases of rerupture were reported at 36 months [11].

\section{Conclusion}

The V-Y plasty of triceps tendon brachii improved the functional prognosis of the elbow. It's a simple technique to promote.

\section{Conflict of Interest}

The authors state that there is no conflict of interest. The patient was informed and gave contentment for this article.

\section{Author's Contribution}

All the authors contributed to the writing of this manuscript, and had read and approved the final version. 


\section{References}

[1] Sanchez-Sotolo, J. and Morrey, B.F. (2002) Surgical Techniques for Reconstruction of Chronic Insufficiency of the Triceps. The Journal of Bone and Joint Surgery, 84, 1116-1120. https://doi.org/10.1302/0301-620X.84B8.12902

[2] Dos Remedios, C., Brosset, T., Chantelot, C. and Fontaine, C. (2007) Réparation d'une rupture complète du triceps brachial par greffe tendineuse au DIDT. A propos d'un cas et revue de la littérature. Chirurgie de la main, 26, 154-158. https://doi.org/10.1016/j.main.2007.05.006

[3] Wolf, J.M., Mc Carty, E.C. and Ritchie, P.D. (2008) Triceps Reconstruction Using Hamstring Graft for Triceps Insufficiency or Recurred Rupture. Technique in Hand \& Upper Extremity Surgery, 12, 174-179. https://doi.org/10.1097/BTH.0b013e31817da1ba

[4] Yazdi, H.R., Qomashi, I. and Hoseni, M.G. (2012) Neglected Triceps Tendon Avulsion: Case Report, Literature Review, and a New Repair Method. The American Journal of Orthopedics, 41, E96-E99.

[5] Tiger, E., Mayer, D.P. and Glazer, R. (1993) Complete Avulsion of the Triceps Tendon: MRI Diagnosis. Computerized Medical Imaging and Graphics, 17, 51-54. https://doi.org/10.1016/0895-6111(93)90074-W

[6] Wagner, J.R. and Cooney, W.P. (1997) Rupture of the Triceps Muscle at the Musculo-Tendinous Junction: A Case Report. Journal of Hand Surgery, 22, 341-343. https://doi.org/10.1016/S0363-5023(97)80175-X

[7] De Waal Malefit, M.C. and Beeker, T.W. (1987) Avulsion of the Triceps Tendon in Secondary Hyperparathyroidism. A Case Report. Acta Orthopaedica Scandinavica, 58, 434-435. https://doi.org/10.3109/17453678709146376

[8] Stannard, J.P. and Bucknell, A.L. (1993) Rupture of the Triceps Tendon Associated with Steroid Injections. The American Journal of Sports Medicine, 21, 482-485. https://doi.org/10.1177/036354659302100327

[9] Pina, A., Gardia, I. and Sabater, M. (2002) Traumatic Avulsion of Triceps Brachii. Journal of Orthopaedic Trauma, 16, 273-276. https://doi.org/10.1097/00005131-200204000-00010

[10] Thomas, J.R. and Lauton, J.N. (2017) Biceps and Triceps Rupture in Athletes. Hand Clinics, 33, 35-46. https://doi.org/10.1016/j.hcl.2016.08.019

[11] Dunn, J.C., Kusnezov, N., Fares, A., Rubin, S., Orr, J. and Friedman, D. (2017) Triceps Tendon Rupture: A Systematic Review. Hand, 12, 431-438.

https://doi.org/10.1177/1558944716677338 